\title{
Ultrasound-Assisted Extraction Process of Polysaccharides from Okra Assisted By Response Surface Methodology
}

\author{
Zhanliang Zhai, Lin Tang*, Xiaohui Liu, Xin Gao and Jingjing Jia \\ Food Engineering, Life Science College, Shandong Normal University, Jinan, China
}

\begin{abstract}
The extraction of polysaccharides from okra pods by ultrasound-assisted heating extraction was investigated using response surface methodology (RSM). The optimized conditions were ultrasonic temperature $63.19{ }^{\circ} \mathrm{C}$, ultrasonic time of $\mathbf{1 0 . 0 4}$ $\mathrm{min}$, liquid/solid ratio of 47.39: 1 (mL:g).The experimental optimized yield was $6.375 \%$, which was well matched with the predicted value $(6.435 \%)$.monosaccharide composition has been analyzed by Gas chromatography(GC).
\end{abstract}

Keywords-okra;polysaccharides; ultrasonic; response surface method; GC

\section{INTRODUCTION}

The okra plant, a native plant from Africa, is now grown in many other areas such as parts of china [1].The okra pods are often used as a vegetable. Its water extracts contain thick slimy polysaccharides and are used to thicken soups and stews[2].In recent years, polysaccharides is suggested to possess various pharmaceutical activities including increased immunity[3],anti-fatigue, anti-tumor, as well as anti-oxidation, lowering blood pressure [4], etc. Okra polysaccharides are also used as egg white substitute[5], fat substitute [6] in chocolate frozen dairy dessert, and in chocolate bar cookies[7]. In the current study, RSM [8]was employed to study the extraction of okra polysaccharides using ultrasound-assisted heating extraction, aiming at optimizing the conditions for the extraction of polysaccharides from okra pods.

\section{MATERIAL AND METHOD}

\section{A. Material and Chemical Reagents}

Fresh okra pods $\left(-18^{\circ} \mathrm{C}\right.$ cryopreservation). All chemical reagents, including 95\% ethanol, acetone, anhydrous ether , etc., used in the experiments were all analytical grade.

\section{B. Apparatus}

High-speed refrigerated centrifuge(Centrifuge 5810 R Germany),Rotary evaporator(IKA RV 10 digital Germany IKA), Vacuum pump(Vogelherd 20 Germany ILMVAC $\mathrm{GmbH}$ ),Electric oven thermostat blast(Shanghai), Ultrasonic cleaning( KQ500E Kunshan Ultrasonic Instrument Co., Ltd.),Analytical Balances(Sartorius Beijing ) et al.

\section{Methods}

1) Okra polysaccharides extraction process

$\begin{array}{cccc}\text { Dried } & \text { Smash } & \text { Extract } & \text { Centrifugal } \\ \downarrow & \downarrow & \downarrow & \downarrow \\ \text { Okra pods } & \rightarrow & \rightarrow \text { Dry materials } & \rightarrow \text { Mixture }\end{array}$

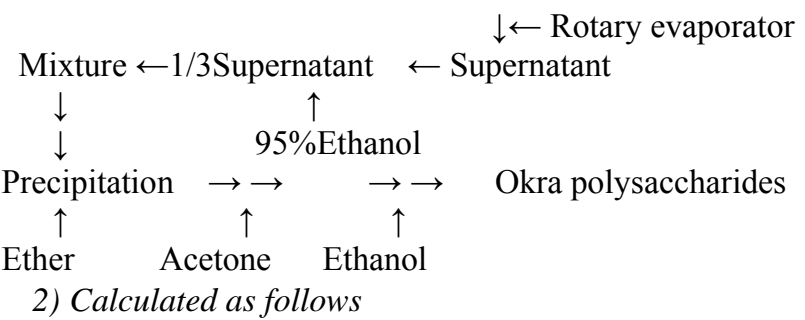

$$
\text { yield }(\%)=\frac{P 1(g)}{P 2(g)} * 100 \%
$$

\section{3) Single factor experiment}

According to preliminary results, three factors which were ultrasonic temperature, ultrasonic time and solid-liquid ratio were selected for the single factor experiment to investigate the impact of each single factor on the extraction rate.

4) RSM ultrasound-assisted extraction process of polysaccharides

RSM with Box - Behnken design (BBD) was used to determine the optimal conditions for polysaccharides extraction from okra pods, A three-level-three-factor BBD was employed to explore the best combination of three independent factors affecting extraction process.

\section{Monosaccharide Composition Analysis}

The monosaccharide composition of pure sample was analysed as described by GC[9].

\section{RESULTS AND DISCUSSION}

\section{A. Single Factor Experiment}

\section{1) Effect of ultrasound temperature}

As shown in figure 1, the decline of the yield might be due to the molecular structure of the polysaccharide damaged to form oligosaccharides or monosaccharides at high temperature, or ultrasound accelerates molecular oscillation and causes temperature rise, at the same time, It may also be that the high temperature result in reducing sugars react with proteins and accelerate the decomposition of polysaccharides. So ultrasonic temperature selected $60{ }^{\circ} \mathrm{C}$. 


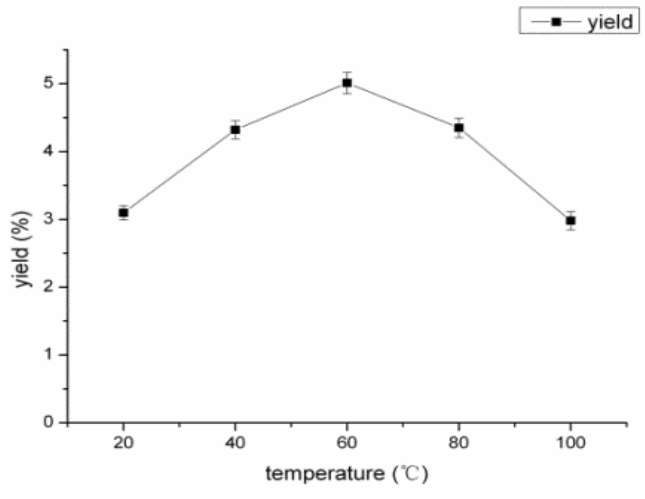

FIGURE I. EFFECT OF TEMPERATURE ON THE ULTRASONIC EXTRACTION RATE OF POLYSACCHARIDES OKRA

\section{2) Effect of ultrasonic time}

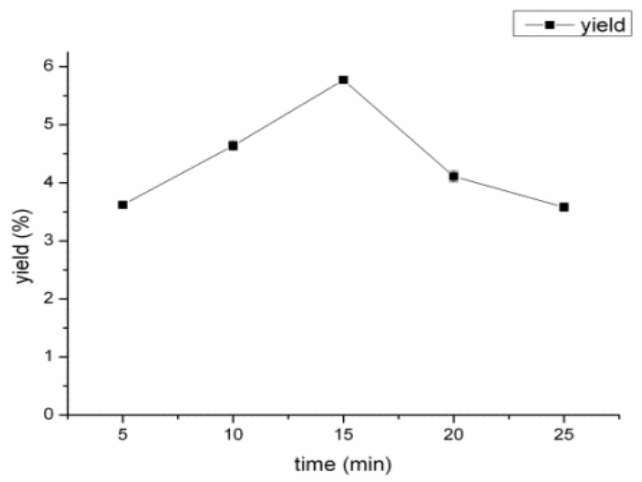

FIGURE II. EFFECT OF ULTRASONIC TIME ON THE ULTRASONIC EXTRACTION RATE OF POLYSACCHARIDES OKRA

As shown in figure 2, when the extraction time is short, the product dissolves insufficiently; however when the extraction time is too long, macromolecular polysaccharide fracture occurs under strong shear ultrasonic, and loss phenomenon occurs after processing. In the meantime, the increased time causes temperature of extract increasing, which could damage the molecular structure of the polysaccharide. So ultrasonic time selection $10 \mathrm{~min}$.

\section{3) Effect of liquid ratio}

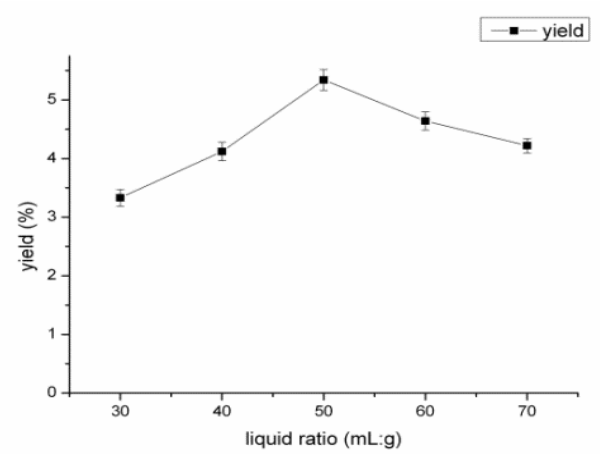

FIGURE III. EFFECT OF LIQUID/SOLID RATIO ON THE EXTRACTION RATE OF POLYSACCHARIDES OKRA
Figure 3 shows that with the increase of the liquid/solid ratio, the extraction rates elevates obviously. When it arrives at 50:1, the extraction rate reaches at the peak value. Soon afterwards, the extraction rate reduced slowly with increase of the liquid/solid ratio. This maybe the weaken of cavitation effect due to the decreasing concentration of solute lead to the reduction of the extraction rate.

\section{B. Analysis of Response Surfaces}
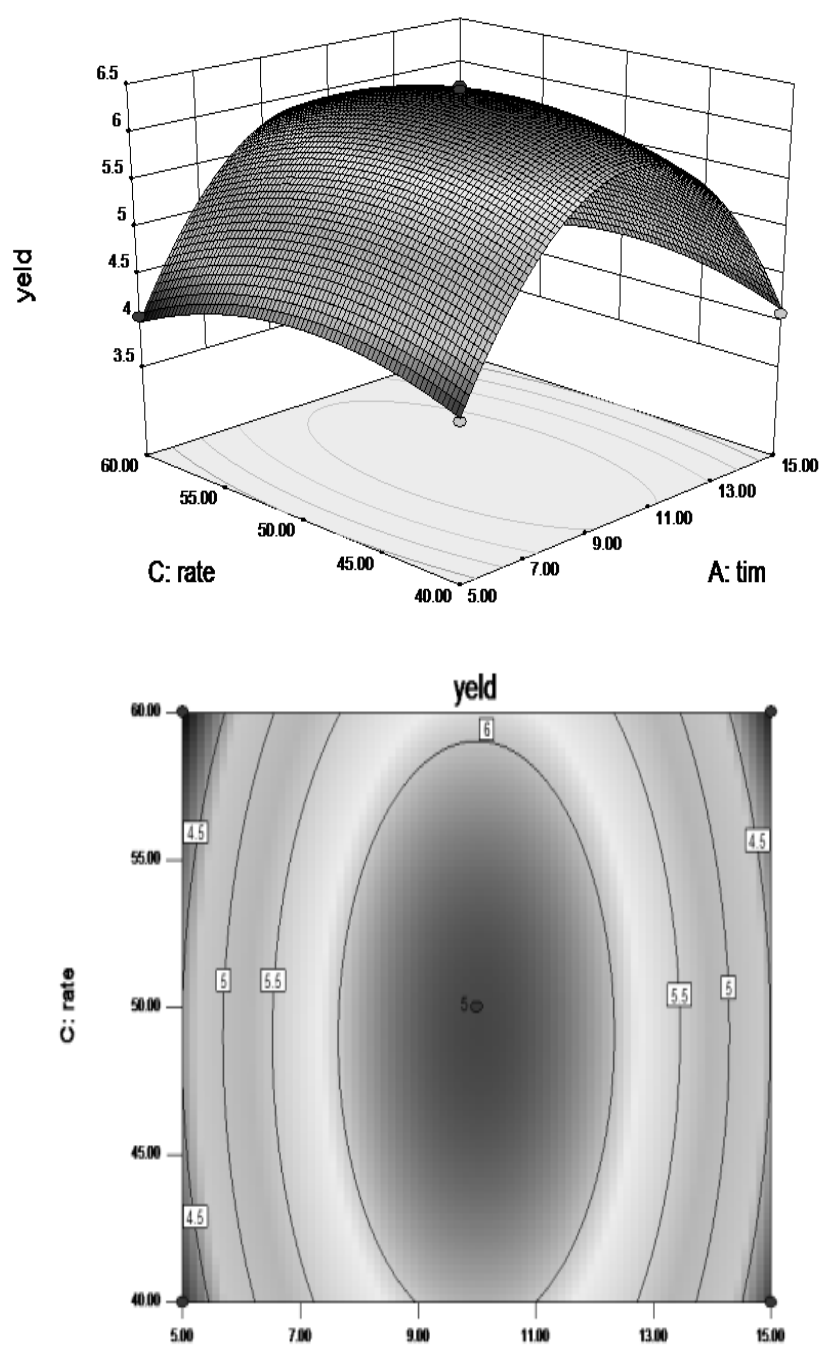

FIGURE IV. ULTRASONIC RESPONSE TIME AND THE RATIO OF WATER SURFACE TO THE IMPACT OF THE EXTRACTION RATE OF POLYSACCHARIDES AND CONTOUR MAPS 

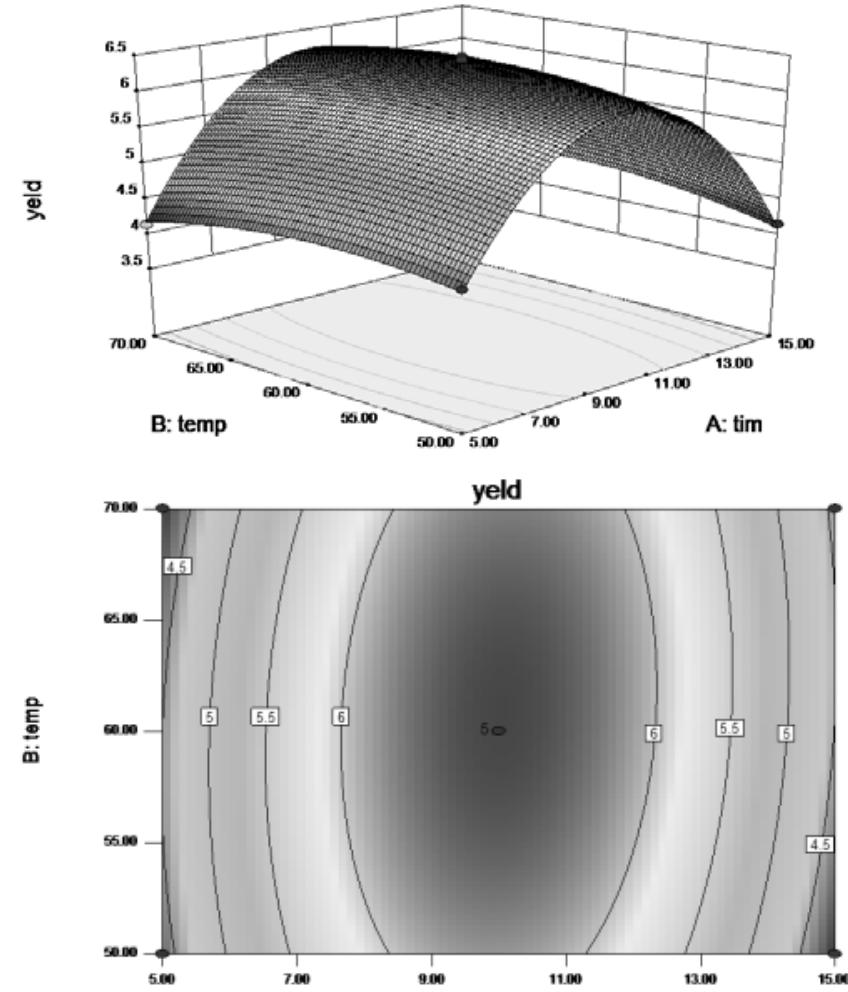

FIGURE V. RESPONSE SURFACE AND CONTOUR FIGURE 6 ULTRASONIC EXTRACTION TIME AND TEMPERATURE ON THE EXTRACTION RATE OF POLYSACCHARIDES IMPACT

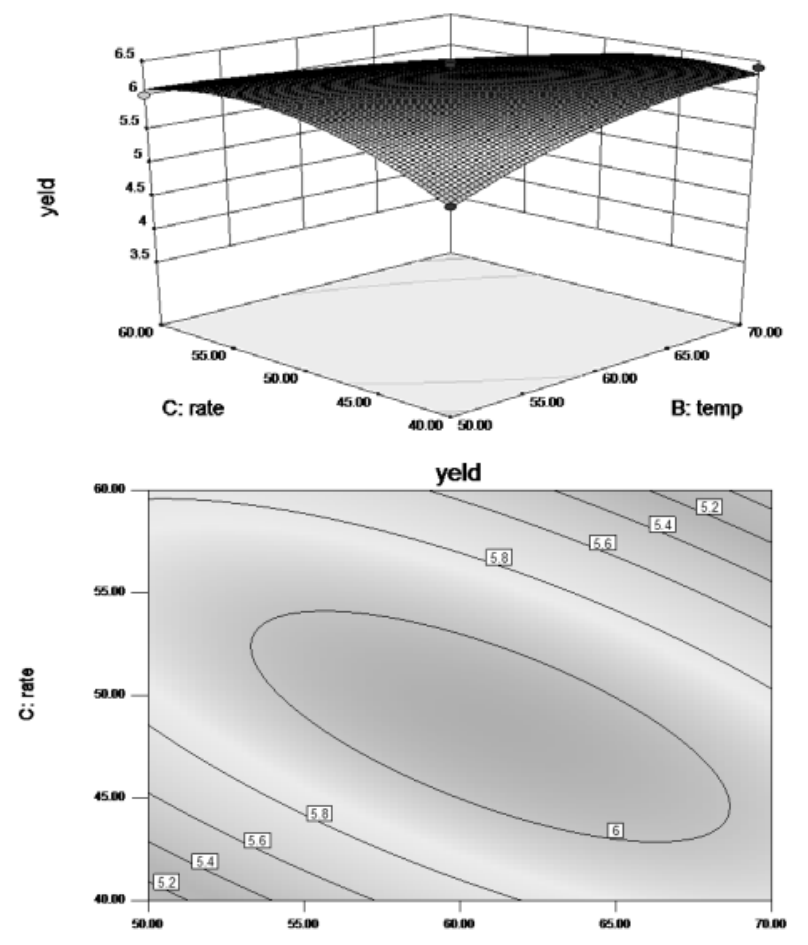

FIGURE VI. RESPONSE SURFACE AND CONTOUR LIQUID RATIO AND EXTRACTION TEMPERATURE ON THE EXTRACTION RATE OF POLYSACCHARIDES

\section{Optimization of Uahe Parameters and Validation of the Model}

As the BBD shows, the optimal extraction conditions for achieving the maximal yield of polysaccharides obtained by differentiation of the quadratic polynomial model were as follows: liquid/solid ratio is $47.39: 1$, extraction temperature is $63.19{ }^{\circ} \mathrm{C}$ and the extraction time is $10.04 \mathrm{~min}$; the predicted maximal yield corresponding to these conditions was $6.435 \%$. However, the optimal extraction conditions were slightly modified as follows: liquid/solid ratio of 47:1, extraction temperature of $63{ }^{\circ} \mathrm{C}$, and the extraction time of $10 \mathrm{~min}$. The experimental yield of polysaccharides was $6.375 \%$, which was close to the predicted value. This result further confirmed that the model was adequate for predicting the yield of polysaccharides using UAHE. 3.6Monosaccharide composition analysis by GC

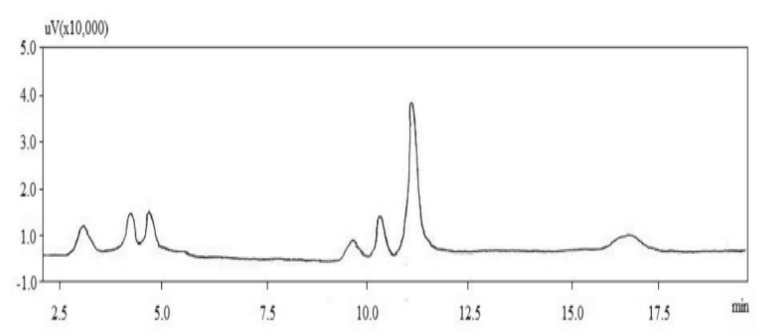

FIGURE VII. THE MONOSACCHARIDE COMPOSITION OF POLYSACCHARIDES ANALYSISED BY GC

According to the standard monosaccharide gas chromatogram, the figure shows that the first peak occurs around 3 minutes is gluconate, in 4 minutes or so there is the rhamnose, in 5 minutes or so represents arabinose, near 9 minutes is xylose, a little more than 10 minutes are glucose, galactose peak represents 11 minutes, the last peak represents fucose. Monosaccharide analysis results are consistent with the traditional extraction method, an ultrasonic does not change Okra polysaccharide monosaccharide composition of polysaccharide structure is not destroyed.

\section{Conclusions}

This study identifies the optimum extraction parameters polysaccharide, and analyze the monosaccharide composition.

\section{REFERENCE}

[1] Savello P A, Martins F.Hull W.Nutrition composition o okra seed meals[J]. Journal of Agricultural and Food Chemistry, 1980, (8) 1163-1166.

[2] Tongjaroenbuangam W R uksee N Chantiratikul P. Neuroprotective effects of quercetin, rutin and okra( Abelmoschus esculentus Linn.) in dexamethasone - treated mice [ J] .Neurochemistry International, 2011, 59(5): 677-685.

[3] Baht, U. S., \& Tharathan, R.N.Functional properties of okra (Hibiscus esculentus) mucilage[J].Starch/starke, 1987, 39:165-167.

[4] Nipaporn Sengkhamparn , Leonard M.C. Sagis , Renko de Vries ,et al .Physicochemical properties of pectins from okra (Abelmoschus esculentus (L.) Moench)[J].Food Hydrocolloids, 2010, 24:35-41.

[5] Costantino, A. J. \& Romanchick-Cerpoviez, J. E. Physical and sensory measures indicate moderate fat replacement in frozen dairy dessert is 
feasible using okra gum as a milk-fat ingredient substitute. [J]. Am. Diet. Assoc, 2004, 104(Suppl.2).

[6] Sheu S C, Lai M H. Composition analysis and immunomodulatory effect of okra ( Abelmoschus esculentus L.) extract[J]. Food Chemistry, 2012, 134(4):1906-1911.

[7] Arslan, N., \& Togrul, H. Filtration of pectin extract from grapefruit peel and viscosity of pectin solutions. Journal of Food Engineering,1996, 27(2), 191-201.

[8] Srivastava, P., \& Malviya, R.. Sources of pectin, extraction and its applications in pharmaceutical industry-An overview. Indian Journal of Natural Products and Resources, 2011, (2):11-18.

[9] Peter Albersheim, Donald J. Nevins, Patricia D. English, Arthur Karr. A method for the analysis of sugars in plant cell-wall polysaccharides by gas-liquid chromatography. Carbohydrate Research 1967, 340-345 